\title{
Qualidade microbiológica de mãos e luvas e avaliação higiênico- sanitária dos manipuladores de alimentos em uma praça de alimentação em Teixeira de Freitas-BA
}

\author{
Microbiological quality of hands and gloves and evaluation hygienical- \\ sanitary of the food handlers in a feeding's square \\ in Teixeira de Freitas city, Bahia
}

Natália de Tartler, ${ }^{*}$ Jorge Luiz Fortuna**

\begin{abstract}
Resumo
Avaliaram-se as condições higiênico-sanitárias das mãos e luvas dos manipuladores de alimentos, através da pesquisa de coliformes totais e termotolerantes, utilizando a técnica do Número Mais Provável (NMP) e pesquisa de Escherichia coli, utilizando suabes das mãos e luvas dos manipuladores. Das 104 (100\%) amostras de mãos e luvas, 43 (41,35\%) apresentaram contaminação por coliformes totais e $18(17,31 \%)$ por coliformes termotolerantes. Das $74(100 \%)$ amostras coletadas das mãos, 21 (28,38\%) apresentaram contaminação por coliformes totais e sete $(9,46 \%)$ por coliformes termotolerantes. Das 30 (100\%) amostras das luvas, $22(73,33 \%)$ se encontravam contaminadas por coliformes totais e $11(36,67 \%)$ por coliformes totais e termotolerantes. A espécie $E$. coli foi identificada em duas amostras de luvas. Conclui-se que a qualidade higiênica e higiênico-sanitária é insatisfatória, pois $21(56,76 \%)$ manipuladores apresentaram algum tipo de contaminação, seja por coliformes totais, termotolerantes ou E. coli.
\end{abstract}

Palavras-chave: manipuladores de alimento; coliformes; higiene.

\begin{abstract}
One evaluated the hygienical-sanitary conditions of the hands and gloves of the food handlers, through the research of total and thermotolerant coliforms, using the technique of Most Probable Number (MPN) and research of Escherichia coli, using swabs of the hands and gloves of the food handlers. Of the 104 samples of hands and gloves, $41.35 \%$ had presented contamination for total coliforms and $17.31 \%$ for thermotolerant coliforms. Of the 74 collected samples of the hands, $28.38 \%$ had presented contamination for total coliforms and $9.46 \%$ for thermotolerant coliforms. Of the 30 samples of the gloves, $73.33 \%$ if found contaminated by total coliforms and $36.67 \%$ for total and thermotolerant coliforms. Species E. coli was identified in two samples of gloves. One concludes that the hygienical and hygienical-sanitary quality is unsatisfactory, therefore $56.76 \%$ food handlers had presented some type of contamination, either for total, thermotolerant coliforms or E. coli.
\end{abstract}

Keywords: Food Handlers; Coliforms; Hygiene.

\section{Introdução}

O desenvolvimento das cidades e a falta de tempo disponível para preparar sua própria refeição tornam cada vez maior o número de pessoas que se alimentam fora de casa. Somando a isso barracas, trailers e quiosques, tornaram-se comuns em praças e ruas das cidades nos últimos anos. Sendo assim, a Agência de Vigilância Sanitária (ANVISA), publicou através da Resolução da Diretoria Colegiada (RDC), um Regulamento Técnico de Boas Práticas para Serviços de Alimentação, a RDC n०216 de 15 de setembro de 2004 do Ministério da Saúde (Brasil, 2004). Nesta resolução consta a definição de que os procedimentos que devem ser adotados por serviços de alimentação, a fim de garantir a qualidade higiênico-sanitária e a conformidade dos alimentos preparados com a legislação vigente.

Atualmente o consumo de alimentos vendidos nas ruas (street food) é um hábito cultural disseminado pelo mundo todo (Okura et al., 2005). Além disso, tal mudança no comportamento do consumidor colaborou para o desenvolvimento do comércio de refeições e trouxe uma preocupação a mais para os profissionais responsáveis pela Vigilância Sanitária: garantir a qualidade higiênico-sanitária dessas refeições (Bellizzi et al., 2005).

A não utilização das medidas higiênico-sanitárias poderá, consequentemente, levar a uma contaminação em água

\footnotetext{
* Licenciada em Ciências Biológicas pela Universidade do Estado da Bahia (UNEB) - Campus X. Bolsa de Iniciação Científica pela Fundação de Amparo à Pesquisa do Estado da Bahia (FAPESB).

** Docente da Universidade do Estado da Bahia (UNEB), Campus X (Teixeira de Freitas-BA), responsável pelas seguintes disciplinas: Microbiologia; Biologia dos Fungos; Microbiologia dos Alimentos; Imunologia; Bioética. Doutorando em Higiene e Processamento de Produtos de Origem Animal (POA) na Universidade Federal Fluminense (UFF). (jfortuna@uneb.br).
} 
de abastecimento e/ou qualquer tipo de alimento, sendo assim considerados fonte de agentes etiológicos de doenças alimentares aos consumidores.

Este trabalho foi desenvolvido em Teixeira de Freitas-BA, com objetivo geral de avaliar as condições higiênico-sanitárias dos manipuladores de alimentos comercializados nos logradouros deste município, através da pesquisa de coliformes totais e termotolerantes pela técnica do Número Mais Provável (NMP), e identificar a espécie Escherichia coli, utilizando suabes das mãos dos manipuladores.

Diante deste possível risco à saúde pública, justificou-se este trabalho, relacionando-o aos aspectos higiênico-sanitários inadequados de manipuladores dos alimentos que possam servir de veículos determinando toxinfecções alimentares aos ingestores.

\section{Material e métodos}

Inicialmente foi realizado um diagnóstico higiênico-sanitário como instrumento de medição de qualidade. Utilizou-se o guia de verificação ou check-list, que foi aplicado junto aos manipuladores de alimentos, englobando aspectos sobre os manipuladores, as instalações, armazenamento dos alimentos, higiene pessoal e as técnicas utilizadas para manipular os alimentos. A classificação final foi atribuída de acordo com a quantidade de respostas "sim", pois significa que contempla as qualidades analisadas no check-list.

O check-list permite fazer avaliação preliminar das condições higiênico-sanitárias do estabelecimento de produção de alimentos, levantando dados críticos ou não (Genta et al., 2005).

Foi também realizado o levantamento sobre a destreza dos manipuladores, ou seja, qual das mãos os manipuladores apresentavam maior agilidade e habilidade, classificando-os em destros ou canhotos. A partir desses dados, foi analisada se a ocorrência de contaminação é maior nas mãos que são frequentemente mais usadas.

Os métodos de análises bacteriológicos empregados foram baseados nos recomendados pela Associação Americana de Saúde Pública (American Public Health Association) (APHA, 2001).

Para a coleta de 104 amostras (74 de mãos e 30 de luvas) foram utilizados suabes (zaragatoas) esterilizados, contidos em tubos de ensaio contendo Solução Salina Peptonada (SSP) a $0,1 \%$ e transportados em recipiente isotérmico, com gelo, até o Laboratório de Microbiologia do Campus X da Universidade do Estado da Bahia (UNEB). Os suabes foram friccionados nas regiões palmar, dorsal e entre os dedos das mãos e luvas dos manipuladores.

Para análise microbiológica foi utilizada a técnica do Número Mais Provável (NMP), onde se adicionou 1,0 mL da amostra inicial em 9,0 mL de (SSP) obtendo a diluição de $10^{-1}$, e a partir dessa diluição utilizando o mesmo procedimento, foram obtidas as diluições de $10^{-2}$ e $10^{-3}$.

Foram três séries de três tubos, com tubo de Durhan, totalizando nove tubos contendo Caldo Lauril Sulfato Triptose (LST), onde foram adicionados $1,0 \mathrm{~mL}$ de cada diluição, e incubados a $35^{\circ} \mathrm{C} / 24-48$ horas. Aqueles que apresentaram formação de gás no interior do tubo de Durhan e tornaram o meio turvo, foram considerados positivos.
De cada tubo positivo de LST, transferiu-se uma alíquota para tubos contendo Caldo Verde Brilhante Lactose Bile (VBBL), e incubados a $35^{\circ} \mathrm{C} / 24-48$ horas, para contagem de coliformes totais e uma alíquota para tubos contendo Caldo para Escherichia coli (EC), e incubados em banho-maria com circulação de água a $45^{\circ} \mathrm{C} / 24-48$ horas, para contagem de coliformes termotolerantes.

Os tubos positivos do Caldo VBBL e do Caldo EC foram conferidos nas tabelas de NMP para coliformes totais e termotolerantes, respectivamente, permitindo avaliar a qualidade e quantidade microbiológica das mãos e luvas dos manipuladores.

Dos tubos positivos do Caldo EC, foram transferidas com alça de platina, alíquotas que foram inoculadas estriadamente em placas contendo meio ágar Eosina Azul de Metileno (EMB), segundo Levine, e incubadas a $35^{\circ} \mathrm{C} / 24$ horas.

Havendo o crescimento de Unidades Formadoras de Colônias (UFC) nucleadas com centro preto e brilho verde metálico, estas foram transferidas de duas a quatro unidades de cada placa através de alça bacteriológica para meio ágar Padrão para Contagem (APC) inclinado em tubo a $35^{\circ} \mathrm{C} / 24$ horas. Não ocorrendo UFC típicas, mas semelhantes, também foi feita a repicagem para o APC.

Após as incubações, transferiram-se com alçadas alíquotas para meios adequados para realizar provas bioquímicas (Indol, Vermelho de Metila, Voges-Proskauer, Citrato - IMViC) para a caracterização da E. coli.

\section{Resultados e discussão}

A partir da avaliação higiênico-sanitária dos manipuladores realizada através do check-list, baseado na RDC n' 275 (Brasil, 2002), verificou-se que 3,3\% foram classificados como EXCELENTE, 45,1\% BOM, 45\% REGULAR, 3,3\% RUIM e 3,3\% PÉSSIMO (Figura 1). Para essa classificação, foram adotados os seguintes intervalos: $90-100 \%$ (EXCELENTE); 70-89\% (BOM); 50-69\% (REGULAR); 30-49\% (RUIM) e <30\% (PÉSSIMO) (Fortuna et al., 2007).

Foram coletadas amostras de 37 manipuladores, totalizando 104 amostras, sendo 74 das mãos e 30 de luvas. Destes, dez manipuladores usavam luvas somente em uma mão e dez utilizavam nas duas mãos, totalizando 20 manipuladores que utilizavam luvas. Do total de 104 (100\%) amostras, 43 $(41,35 \%)$ apresentaram contaminação por coliformes totais e $18(17,31 \%)$ por coliformes termotolerantes. Das $74(100 \%)$ amostras coletadas das mãos, 21 (28,38\%) apresentaram contaminação por coliformes totais e sete $(9,46 \%)$ por coliformes termotolerantes. E das 30 (100\%) amostras de luvas, 22 $(73,33 \%)$ se encontravam contaminadas, das quais $11(36,66 \%)$ estavam contaminadas somente por coliformes totais e 11 $(36,66 \%)$ por coliformes totais e termotolerantes. A espécie Escherichia coli foi identificada em duas luvas esquerdas de manipuladores destros e canhotos.

Em trabalho realizado por Tomich et al. (2005), para avaliar as boas práticas de fabricação em indústrias de pão de queijo, quanto à higienização das mãos dos manipuladores, demonstrou que $34,5 \%$ das amostras apresentaram coliformes termotolerantes.

Outros trabalhos também corroboram aos resultados encontrados nesta pesquisa, já que demonstraram contaminação por coliformes totais e termotolerantes em mãos de manipuladores 


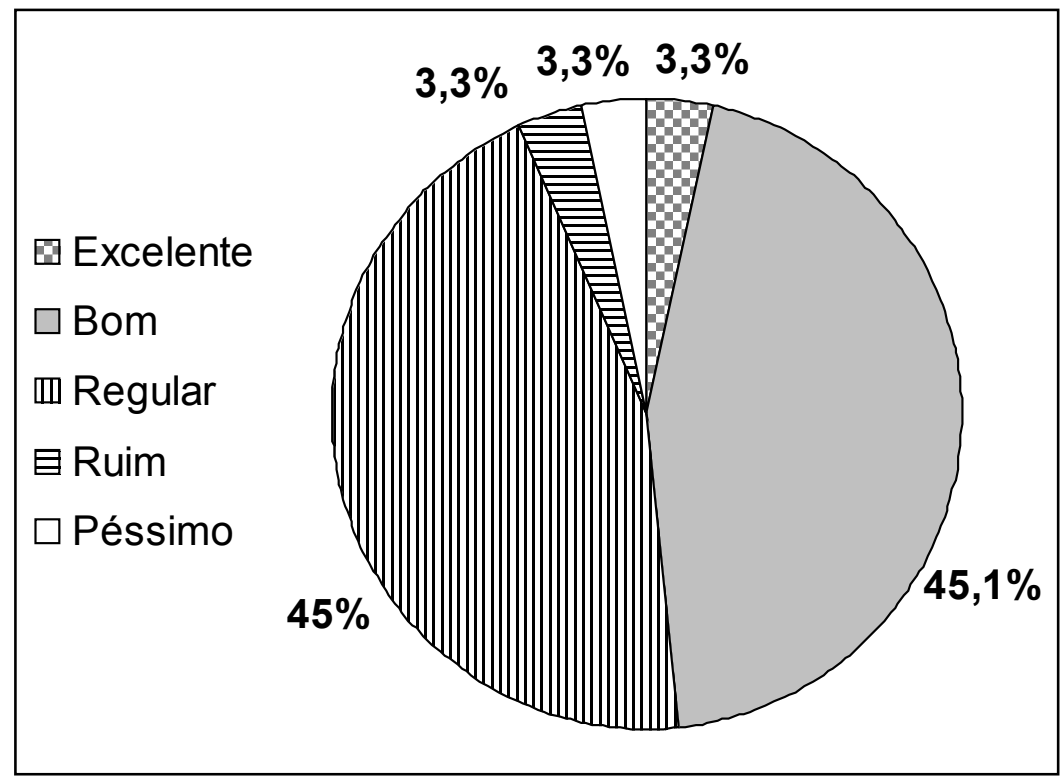

Figura 1: Resultado da avaliação higiênico-sanitária dos manipuladores de alimentos a partir do check list. Teixeira de Freitas-BA. Julho 2008.

de alimentos, tais como Millezi et al. (2007), que avaliaram a qualidade microbiológica das mãos de 22 manipuladores na indústria de alimentos, encontrando duas $(9,1 \%)$ amostras contaminadas por coliformes termotolerantes e dez (45,5\%) por coliformes totais e Fortuna (2002) que encontrou o mesmo resultado $(9,1 \%)$ para coliformes termotolerantes ao analisar as mãos de 22 merendeiras de instituições de ensino municipais e estaduais do Rio de Janeiro.

Porém, outros trabalhos semelhantes não encontraram contaminação por coliformes em mãos de manipuladores de alimentos. Como pesquisa realizada por Borges (2010) que analisou 14 amostras de mãos de manipuladores das indústrias de conservas de champignon, da região metropolitana de Curitiba-PR e não encontrou nenhuma contaminação por coliformes termotolerantes, também Munhoz (2006), que pesquisou 19 amostras de mãos de manipuladores de merenda escolar em diferentes escolas municipais de Botucatu-SP não apresentando contaminação de coliformes totais e termotolerantes.

Dos $68(100 \%)$ testes bioquímicos (IMViC), realizados para pesquisa de Escherichia coli, quatro $(5,87 \%)$ apresentaram leitura $(++--)$, caracterizando a presença de E. coli na amostra. Os outros possíveis gêneros de Enterobacteriaceae encontrados, através do IMViC, estão listados na Tabela 1. Já em estudo realizado por Shojaei et al. (2006), com manipuladores de alimentos, mostrou que $109(72,7 \%)$ dos 150 manipuladores apresentavam-se contaminados com uma ou mais bactérias patogênicas, sendo que $22 \%$ eram por E. coli.

A partir da análise realizada sobre a destreza dos manipuladores, neste trabalho verificou-se que as amostras que apresentaram resultados positivos em relação a coliformes totais e termotolerantes evidenciaram que existe uma contaminação maior e mais frequente nas mãos e/ ou luvas (direita ou esquerda) que são mais usadas na manipulação dos alimentos.
De 32 (100\%) manipuladores destros, 16 (50\%) tiveram contaminação por coliformes totais, destes 16 , dez $(62,5 \%)$ estavam com maior contaminação nas mãos e/ou luvas direitas, três $(18,75 \%)$ mostraram contaminação na mão e/ ou luva esquerda e três $(18,75 \%)$ mostraram igualdade no nível de contaminação entre as mãos e/ou luvas (Figura 2). Dos nove $(28,12 \%)$ manipuladores que apresentaram contaminação por coliformes termotolerantes, sete $(77,78 \%)$ tiveram maior contaminação nas mãos e/ou luvas direitas e apenas dois $(22,22 \%)$ não tiveram relação entre contaminação e destreza (mão mais utilizada na manipulação do alimento) (Figura 3).

Dos quatro (100\%) manipuladores analisados que foram classificados como canhotos, um (25\%) manipulador teve contaminação por coliformes totais nas mãos e/ou luvas esquerdas, um $(25 \%)$ não apresentou relação entre contaminação e destreza e dois $(50 \%)$ apresentaram igualdade ao nível de contaminação entre as mãos e/ou luvas (Figura 2). Em se tratando de coliformes termotolerantes, dois $(50 \%)$ manipuladores estavam contaminados. Destes dois, um (25\%) apresentou contaminação nas mãos e/ou luvas esquerdas (Figura 3).

Tabela 1: Possíveis gêneros de Enterobacteriaceae encontrados a partir dos testes bioquímicos de Indol. Vermelho de Metila, Voges-Proskeur e Citrato (IMViC). Teixeira de Freitas-BA. Julho 2008

\begin{tabular}{c|c|c|c}
\hline IMVC & $\begin{array}{c}\text { Incidência } \\
\text { (n) }\end{array}$ & $\begin{array}{c}\text { Frequência } \\
(\%)\end{array}$ & Possíveis Gêneros \\
\hline--++ & 28 & 41,2 & Enterobacter / Serratia / Klebsiella \\
++++ & 13 & 19,1 & Hafnia / Serratia / Proteus \\
-+++ & 10 & 14,7 & Arizona / Citrobacter / Salmonella \\
--++ & 10 & 14,7 & Klebsiella \\
++-- & 4 & 5,9 & Escherichia / Ewardsiella / Shigella \\
++++ & 3 & 4,4 & Providencia / Proteus \\
\hline TOTAL & $\mathbf{6 8}$ & $\mathbf{1 0 0 , 0}$ & Família Enterobacteriaceae \\
\hline
\end{tabular}

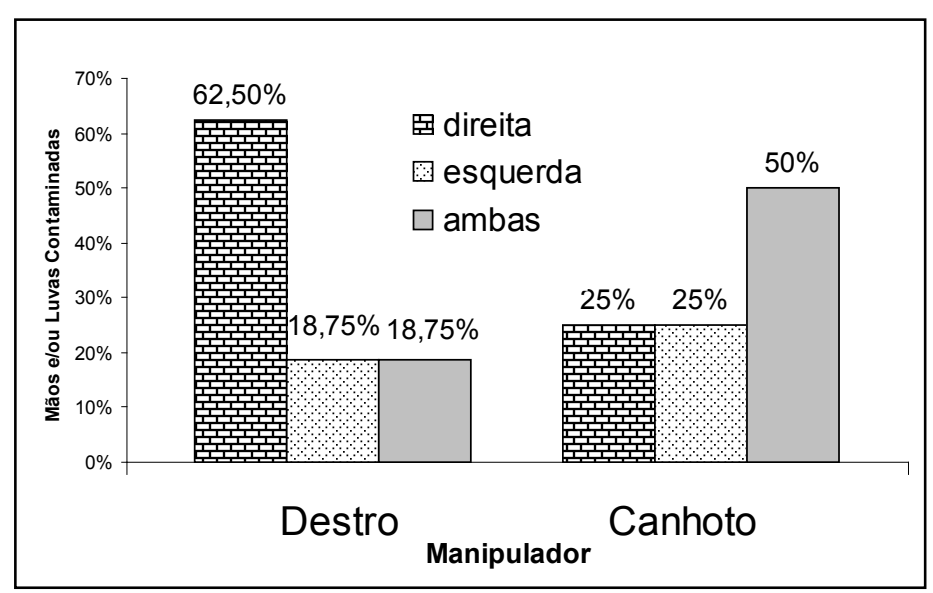

Figura 2: Gráfico ilustrando manipuladores (destros e canhotos) que apresentaram contaminação por coliformes totais e suas respectivas mãos e/ou luvas que apresentaram maior contaminação. Teixeira de Freitas-BA. Julho 2008. 


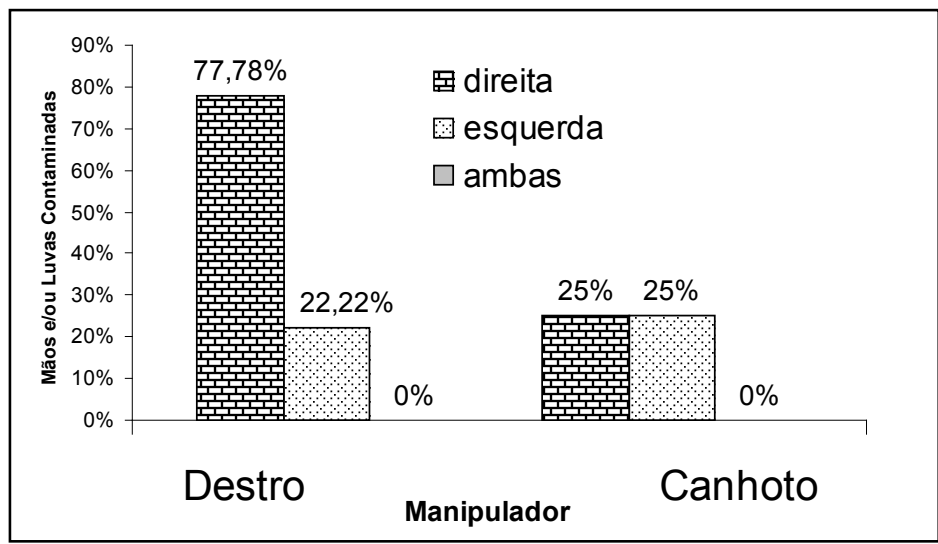

Figura 3: Gráfico ilustrando manipuladores (destros e canhotos) que apresentaram contaminação por coliformes termotolerantes e suas respectivas mãos e/ou luvas que apresentaram maior contaminação. Teixeira de Freitas-BA. Julho 2008.

O único manipulador que foi classificado como ambidestro usava luvas nas duas mãos e apresentou contaminação elevada por coliformes totais e termotolerantes nas luvas e na mão esquerda. Isso poderia ser explicado pela contaminação cruzada que pode ocorrer, pois manipulava e tocava os alimentos, utensílios e equipamentos com ambas as mãos.

Notou-se que não foram todos, mas em uma análise geral é possível afirmar que a contaminação ocorreu com maior frequência nas mãos e/ou luvas que são mais utilizadas para manusear alimentos, equipamentos e utensílios.

A praça onde foi realizada a pesquisa não dispõe de estrutura com sistema de tratamento de água encanada e esgoto, o que dificulta a higienização das mãos por parte dos manipuladores de alimentos, favorecendo assim a contaminação de alimentos e consequentemente as toxinfecções alimentares.

Estes dados tornam-se importantes, pois, de acordo com Pistore e Gelinskib (2006), as instalações, equipamentos e utensílios do local de manipulação de alimentos constituem requisitos essenciais para que ocorra uma manipulação adequada, se efetive o cumprimento das boas práticas e se obtenha qualidade higiênico-sanitária dos alimentos servidos. Além disso, Millezi et al. (2007) afirmaram que os padrões higiênicos na manipulação de alimento são essenciais para garantir a qualidade da saúde. A ausência ou ineficiência da higienização das mãos de manipuladores de alimentos é um fator de risco, podendo causar a contaminação do alimento que está sendo manipulado.

Apesar da praça não dispor de água encanada, os manipuladores utilizam o banheiro público da praça ou água de garrafas, baldes ou outros recipientes que eram trazidos por eles, para realizar a lavagem das mãos quando necessário. Os alimentos que são comercializados nesta praça pública são, em geral, lanches, crepes, sanduíches e pizzas; portanto, a manipulação com as mãos é necessária e frequente na preparação desses alimentos.

Para Hazelwood e McLean (1994), deve-se manipular os alimentos somente quando necessário, usando talheres e usar luvas descartáveis do tipo cirúrgico, quando a excessiva manipulação se faz necessária na preparação de sanduíches, salgadinhos etc.

Os manipuladores de alimentos utilizam luvas do tipo descartável de plástico e não do tipo cirúrgico, como é recomendado. Entretanto, sabe-se que se as luvas não forem trocadas com frequência, estas também podem ser contaminadas, oferecendo riscos similares às mãos. Além disso, segundo Lues e Van Tonder (2007), as luvas apresentam um risco maior, se o manipulador de alimentos não lavar as mãos antes de colocá-las, pois o interior e o exterior se tornam contaminados. A lavagem das mãos fica negligenciada ou omitida quando se usa luvas, pois o ambiente interno das luvas sendo morno e úmido, torna-se propício e adequado ao desenvolvimento de bactérias.

Notou-se que a contaminação por coliformes totais e termotolerantes nas luvas foi maior e mais frequente do que nas mãos dos manipuladores. Até mesmo sendo a espécie Escherichia coli identificada em duas amostras de luvas utilizadas pelos manipuladores de alimentos. Para Siqueira (1995), a espécie Escherichia coli, que foi pesquisada, é empregada como indicador de contaminação fecal, pois tem seu hábitat exclusivo no trato intestinal do homem e outros animais.

Os resultados encontrados neste trabalho permitem concluir que a qualidade higiênica e higiênico-sanitária é insatisfatória, pois $56,76 \%$ dos manipuladores apresentaram algum tipo de contaminação, seja por coliformes totais, termotolerantes ou Escherichia coli.

A qualidade deixa de ser satisfatória devido à falta de capacitação de mão de obra qualificada, infraestrutura adequada com abastecimento de água encanada e tratada, assim como rede de esgoto e ao uso inadequado das luvas, sendo pelo tipo de luvas que são utilizadas ou pela frequência com que são trocadas, oferecendo risco à saúde da população que consome alimentos nessa praça.

Com base nos resultados obtidos neste trabalho, acredita-se que grande parte das contaminações poderia ser reduzida ou evitada, com medidas de saneamento básico, água potável para abastecer as barracas, aumentando o nível da educação sanitária, treinando e capacitando os manipuladores com palestras, cursos e treinamentos para que possam praticar hábitos de higiene adequados tanto pessoais quanto para manipular os alimentos.

\section{Agradecimentos}

Agradecimento especial à Fundação de Amparo à Pesquisa do Estado da Bahia (FAPESB) pela Bolsa de Iniciação Científica.

\section{Referências}

APHA. American Public Health Association. Compendium of Methods for the Microbiological Examination of Foods. 4. ed. Washington: APHA. 2001, 676 p.
BELLIZZI, A.; SANTOS, C. L.; COSTA, E. Q.; VERRUMABERNARDI, M. R. Treinamento de manipuladores de alimentos: uma revisão de literatura. Revista Higiene Alimentar. v. 19, n. 132. 2005, p. 36-48. 
BORGES, E. M. J. Avaliação das boas práticas de fabricação de conservas de champignon (Agaricus bisporus (Lange) Singer) produzidas na região metropolitana de Curitiba. 195 f. Dissertação (Mestrado). Programa de Pós-graduação em Tecnologia de Alimentos. Universidade Federal do Paraná (UFPR). Curitiba. 2010.

BRASIL. Agência Nacional de Vigilância Sanitária do Ministério da Saúde. ANVISA/MS. Resolução da Diretoria Colegiada (RDC) $n^{\circ}$ 216, de 15 de setembro de 2004. Regulamento Técnico de Boas Práticas para Serviços de Alimentação.

BRASIL. Agência Nacional de Vigilância Sanitária do Ministério da Saúde. ANVISA/MS. Resolução da Diretoria Colegiada $(R D C) n^{\circ} 275$, de 21 de janeiro de 2002. Regulamento Técnico de Procedimentos Operacionais Padronizados Aplicados aos Estabelecimentos Produtores/Industrializadores de Alimentos e a Lista de Verificação das Boas Práticas de Fabricação.

FORTUNA, J. L. Aspectos higiênico-sanitários no preparo de carne bovina servida em refeições escolares de instituições municipais e estaduais, no estado do Rio de Janeiro. Revista Higiene Alimentar. v. 16, n. 95,2002 , p. 23-33.

FORTUNA, J. L.; FILHO, J. P.; HOMBRE, J. S.; JESUS, A. G.; CUNHA, A. H.; NEVES, Z. J.; FERREIRA, M. G. N. Diagnóstico higiênico-sanitário dos manipuladores de produtos alimentícios comercializados em uma praça pública do município de Teixeira de Freitas-BA. Revista Higiene Alimentar. v. 21, n. 150, 2007, p. 91.

GENTA, T. M. S.; MAURÍCIO, A. A.; MATIOLI, G. Avaliação das Boas Práticas através de check-list aplicado em restaurantes self-service da região central de Maringá, estado do Paraná. Acta Scientiarum. Health Science. v. 27, n. 2, 2005, p. 151-156.

HAZELWOOD, D.; Mc LEAN, A. C. Manual de Higiene para Manipuladores de Alimentos. São Paulo: Varela. 1994, 140 p.

LUES J. F. R.; VAN TONDER, I. The occurrence of indicator bacteria on hands and aprons of foods handlers in the delicatessen sections of a retail group. Food Control. v. 18. 2007. p. 326-332.
MILLEZI, A. F.; TONIAL, T. M.; ZANELLA, J. P.; MOSCHEN, E. E. S.; ÁVILA, C. A. C.; KAISER, V. L.; HOFFMEISTER, S. Avaliação e qualidade microbiológica das mãos de manipuladores e do agente sanificante na indústria de alimentos. Analytica. n. 28, 2007, p. 74-79.

MUNHOZ, P. M. Qualidade higiênico-sanitária de alimentos e avaliação dos conhecimentos sobre boas práticas por parte dos manipuladores de alimentos da rede municipal de ensino Botucatu, SP. Botucatu: Faculdade de Medicina Veterinária e Zootecnia de Botucatu. Universidade Estadual Paulista (UNESP). 2007. Dissertação (Mestrado em Medicina Veterinária).

OKURA, M. H; JANNINI, A. E.; OLIVEIRA, G. B.; PEREIRA, K. S.; BORGES, L.; FERREIRA, M. G. N.; ALVIM, N. F. M. A. Contaminação em salgados (coxinhas) encontrados no centro da cidade de Úberaba, MG. Revista Higiene Alimentar. v. 19, n. 132, 2005, p. 65-68.

PISTORE, A. R.; GELINSKIB, J. M. L. N. Avaliação dos conhecimentos higiênico-sanitários dos manipuladores de merenda escolar: fundamento para treinamento contínuo e adequado. Revista Higiene Alimentar. v. 20, n. 146. 2006, p. 20.

SHOJAEI, H.; SHOOSHTARIPOOR, J.; AMIRI, M. Efficacy of simple hand-washing in reduction of microbial hand contamination of Iranian food handlers. Food Research International. v. 39, n. 5, 2006, p. 525-529.

SIQUEIRA, R. S. Manual de Microbiologia de Alimentos. Rio de Janeiro: Embrapa, 1995, 159 p.

TOMICH, R. G. P.; TOMICH, P. R.; AMARAL, C. A. A.; JUNQUEIRA, R. G.; PEREIRA, A. J. G. Metodologia para avaliação das boas práticas de fabricação em indústrias de pão de queijo. Ciência e Tecnologia Alimentar. v. 25, n. 1, 2005, p. 115-120. 